Larval Development of Pagurus longicarpus Say Reared in the Laboratory. III. Behavioral Responses to Salinity Discontinuities

Morris H. Roberts Jr. 
Reference: Biol. Bull., $140:$ 489-501. (June, 1971)

\title{
LARVAL DEVELOPMENT OF PAGURUS LONGICARPUS SAY REARED IN THE LABORATORY. III. BEHAVIORAL RESPONSES TO SALINITY DISCONTINUITIES ${ }^{1}$
}

\author{
MORRIS H. ROBERTS, JR. ${ }^{2}$
}

Virginia Institute of Marine Science, Gloucester Point, Virginia 23062

Survival rate, although commonly used as an index of an organism's ability to meet a given environmental challenge (Costlow, Bookhout, and Monroe, 1960, 1962, 1966; Roberts, 1971), is a rather crude estimate of the ability of an organism to adapt to its environment. Behavioral responses associated with the maintenance of an animal in its optinal environment are more suitable measures of adaptability (Shelford, 1915). Orientative behavior reflects, at least in part, the integration of an animal's various adaptive physiological changes in metabolism, reproduction, hormonal balance, etc., to challenges of the external milieu.

Responses of various zooplankters to salinity discontinuities were first studied by Harder (1952a, 1952b, 1954, 1957, 1968). The ability to detect and avoid waters of reduced salinity has now been demonstrated experimentally for several meroplankters as well as holoplankters. A response to salinity discontinuities has been demonstrated in Mercenaria mercenaria trochophores (Turner and George, 1955), Phyllodoce trochophores (Lyster, 1965), some copepods and the zoeal instars of Pisidia longicornis (Lance, 1962), and Zoea I of Homarus americanus (Scarratt and Raine, 1967).

In the present study, the response of Pagurus longicarpus zoeal instars to salinity discontinuities of different magnitudes was examined. The avoidance behavior was described and quantified. The interaction effect of developmental age and magnitude of the discontinuity on the response was examined. Further an attempt was made to determine if the receptor(s) is localized on certain structures.

\section{Materials AND Methods}

The apparatus used to study responses to salinity discontinuities consisted of two plastic cylinders of $7.9 \mathrm{~cm}$ diameter, $46 \mathrm{~cm}$ height, marked off into ten $4 \mathrm{~cm}$ segments and filled to a depth of $40 \mathrm{~cm}$. The volume of each segment was about $198 \mathrm{ml}$. A glass tube was cemented at the bottom of each cylinder through which water could be introduced from a separatory funnel. Two centimeters above the bottom of the cylinder, a canula was inserted through a small neoprene stopper, the tip of the canula reaching to the central axis of the cylinder. Externally the canula was fitted with a short plastic tube and pinch clamp to which a largebore syringe could be attached (Fig. 1).

To establish a discontinuity, about one liter of water of reduced salinity was first poured directly into one column. High salinity water was then slowly

\footnotetext{
${ }^{1}$ Contribution Number 381 from the Virginia Institute of Marine Science, Gloucester Point, Virginia 23062.

2 Present address: Department of Biology, Providence College, Providence, Rhode Island 02918. This paper is part of a dissertation submitted to the School of Marine Science of the College of William and Mary in partial fulfillment of the requirements for the Doctor of Philosophy Degree.
} 
introduced at the bottom from the separatory funnel so as to obtain a sharp gradient between the two layers. A preliminary test with dyes indicated that mixing occurred over a distance of about $2-3 \mathrm{~mm}$ with little increase in the thickness of the mixed layer through time. The second column (unstratified) served as a control.

All tests were conducted in a dark room. Light from a 25 watt incandescent bulb was passed through a $3 \mathrm{~cm}$ diameter hole in an illuminator located $11.5 \mathrm{~cm}$ above the top of each water column, with no lens to concentrate the light beam.

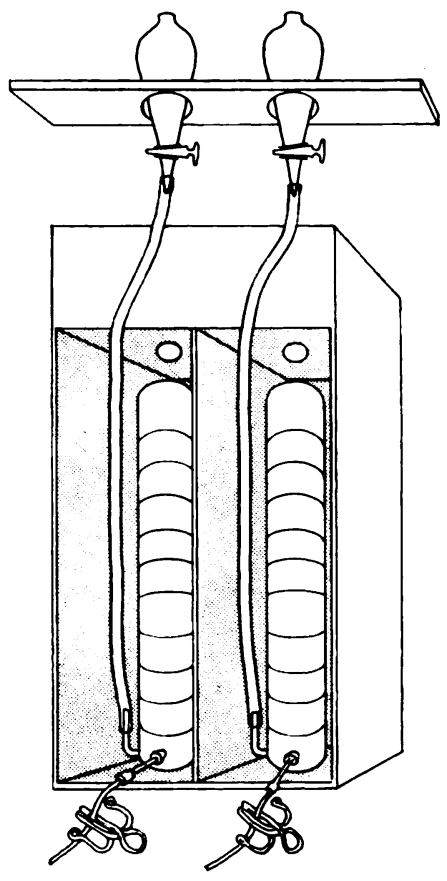

Figure 1. Discontinuity column apparatus, consisting of a plastic cylinder marked off into ten $4 \mathrm{~cm}$ segments. A glass tube cemented into the bottom connects to a separatory funnel from which water is introduced. A canula inserted $2 \mathrm{~cm}$ above the bottom and connected to a syringe permits injection of the larvae into the bottom stratum.

The cylinders were placed in a compartmented wooden box so that each was isolated from extraneous light and from its twin. No difference in light intensity was detected with a Yentsch photometer between the light sources for each column.

Once the desired salinity discontinuity was established, 50 light-adapted zoeae of the desired stage were drawn into a syringe, the syringe was attached to the canula (previously flushed of air) and the larvae were carefully introduced into the test column. Only on rare occasions were any larvae damaged by this procedure, even the large Zoea IV. The control column was always filled first.

During the first 15 minute period, the larvae were observed and notes taken concerning their movements and behavior. After 15, 30, and 60 minutes, the number of larvae visible in each $4 \mathrm{~cm}$ segment was counted and recorded. Some 
larvae were always invisible, either because they were close to the side of the chamber or on the bottom, but this was shown not to affect the results materially in replicate tests. In addition, larvae moved up and down the column during the counting period, but errors from this source are assumed to be negligible although this was not tested. Because of the depth of field, the height of the column, and distortion resulting from the curvature of the cylinder, a photograph would not have produced a significant improvement in obtaining a quantitative record.

In the main series of tests, the salinity in the lower layer $\left(\mathrm{S}_{\mathrm{L}}\right)$ was 30,25 , or $20 \%$. The salinity of the upper layer $\left(S_{U}\right)$ was varied, ranging from $S_{U}=S_{L}$ (control) down to a salinity which no larvae would enter, usually $15 \%$. A specific condition may be abbreviated $\mathrm{S}_{\mathrm{U}} / \mathrm{S}_{\mathrm{L}}$. All tests were conducted at $20^{\circ} \mathrm{C}$, with no thermal gradient. Controls were alternated between each cylinder.
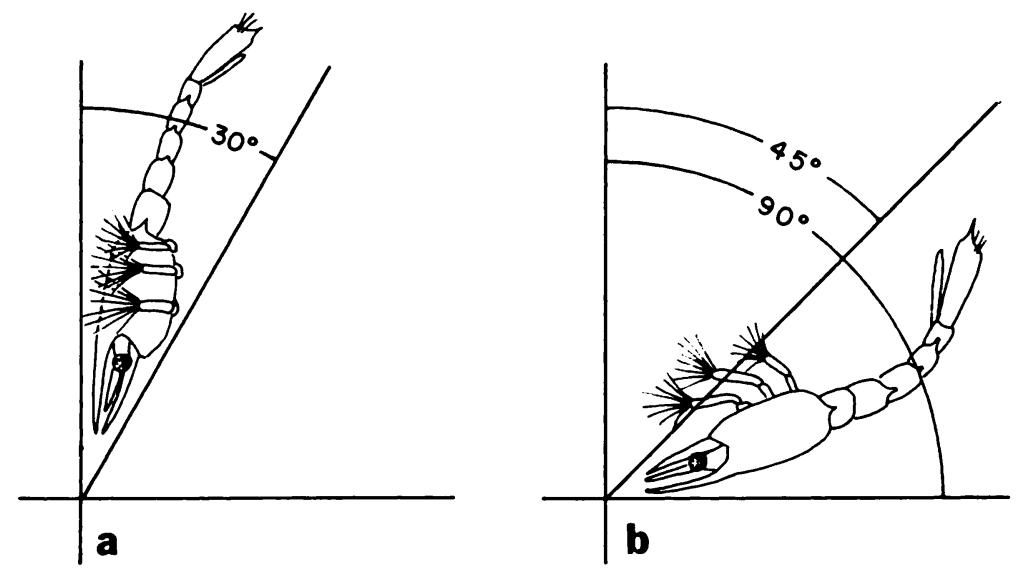

Figure 2. Orientation of zoeal body axes (a) when swimming upward or downward, and (b) when sinking passively. See text for further details.

In one experiment, two unstratified columns were established $(25 / 25)$ with 40 Zoea III in one, 50 in the other, and hourly observations made over a 24 hour period to determine (1) if there was any cyclic pattern to the behavior and (2) if there was a large difference in results between the columns. In a second experiment with two unstratified columns $(25 / 25), 50$ Zoea IV were placed in one column, 25 in the other, to determine whether distribution with depth was a function of larval density.

Larvae for all experiments were reared in large mass cultures (larval density: 1 larva per 5-10 ml) of $1000 \mathrm{ml}$ total volume. Larvae were transferred to clean water and fed nauplii of Artemia daily. Culture salinity corresponded to $\mathrm{S}_{\mathrm{L}}$ for the given experimental series. Culture temperature was $20 \pm 2^{\circ} \mathrm{C}$.

A brief series of experiments was conducted to determine whether the salinity receptors are located on the antennules and antennae, both of which are known to be involved in chemoreception in adult decapods and other crustaceans. Larvae for these tests were reared at $30 \%, 20^{\circ} \mathrm{C}$ to Zoea III. The antennules (A 1) 
and antennae (A 2) were then amputated from 12 larvae with fine insect needles. Three additional larvae had the uropods amputated as a control against operative trauma. All amputees were then maintained individually in compartmented plastic boxes at $30 \%, 20^{\circ} \mathrm{C}$. Survival for the antennectomized group was $50 \%$, for the uropodectomized group $67 \%$. Of the larvae which survived, all successfully molted to Zoea IV. Little or no regeneration was observed in either group of amputees at this stage, but in a series of antennectomies performed on another set of larvae at the same stage of development while developing the operative technique, regeneration of A 1 and A 2 was noted after the molt to the megalopa.

Tests with amputees were performed 24 hours after the operation. The first test was performed to determine whether they could orient in an unstratified column and swim to the surface. Each antennectomized and uropodectomized larva was tested individually for its ability to traverse such a column. Several observations were also made with non-amputees from the same culture. The second test was designed to examine the response of each group of larvae to a stratified column $(15 / 30)$.

\section{RESUlts}

After injection into a control column, zoeae, irrespective of developmental age, oriented with the longitudinal body axis within less than $30^{\circ}$ from the vertical, telson uppermost, ventral surface concave downward (Fig. 2a). In this position, they swam directly upward using the natatory setae on the exopods of the maxillipeds. Upon reaching the surface, the larvae lost their precise orientation and swam in circles. Larvae moving downward usually re-oriented and again swam upward.

In stratified columns, zoeae oriented in the same manner, swimming upward to the discontinuity. Discontinuities of only $2.5 \%$ could be detected and responded to, even though they might ultimately be crossed. After penetrating the upper stratum for $0.5 \mathrm{~cm}$ or so, three distinct responses were observed in decreasing frequency in the order described. The most frequent response was a rapid flexion of the abdomen and telson against the ventral surface and re-extension (hereinafter referred to as telson flip response) which caused a disoriented locomotion. If this brought the larva into the lower stratum, it re-oriented and started the cycle over again. If the telson flip response did not return the larva to the lower stratum, and if the upper layer was not so dilute as to cause continued avoidance responses, the larva re-oriented and swam to the surface. The second response, downward swimming, occurred when the upper layer was more dilute, and the zoea remained in the upper stratum after the telson flip response. A $4 \mathrm{~cm}$ or more penetration into the upper stratum lasting a considerable period, was followed by the third response, passive sinking. Sinking was distinguishable from active downward swimming by the orientation of the longitudinal body axis which ranged from 45 to $90^{\circ}$ from the vertical with the ventral surface concave upward during passive sinking (Fig. $2 \mathrm{~b}$ ).

The percentage of larvae in each $4 \mathrm{~cm}$ segment of the column was plotted against depth for each time period. A representative series of data for Zoea I, $S_{L}=30 \%$, is shown in Figure 3. In the control column, the highest concentration occurred in the uppermost $4 \mathrm{~cm}$ segment, a secondary concentration at the bottom, 
with negligible percentage between. In the $25 / 30$ column, a tertiary concentration was observed in the levels bracketing the discontinuity. In the $20 / 30$ column the primary concentration bracketed the interface with a secondary concentration at the bottom. In the $15 / 30$ column, the primary concentration was located just

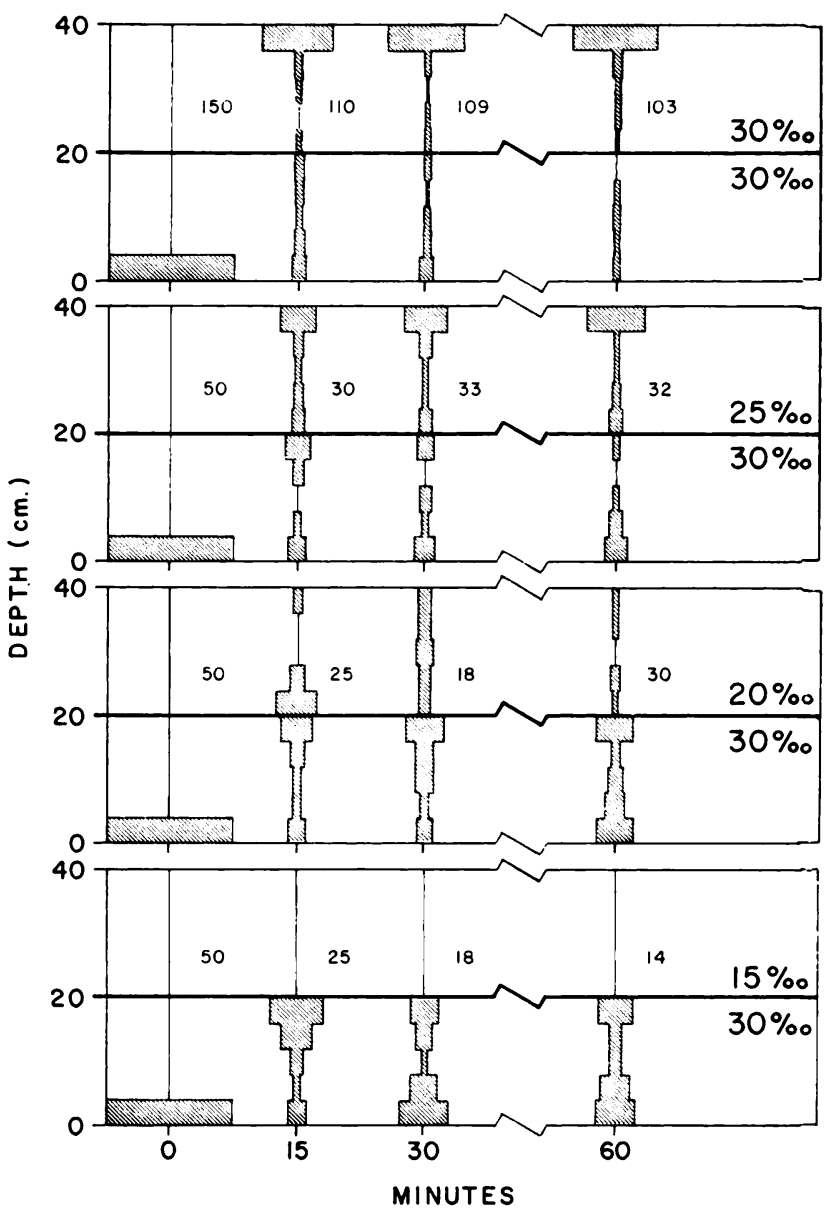

Figure 3. Histograms of detailed depth distribution for Zoea. I. The bar in the bottom $4 \mathrm{~cm}$ interval for time 0 represents $100 \%$. The number to the right of each individual histogram is the total number of larvae observed in the given time interval and served as the base for percentages.

below the interface with no larvae above the discontinuity. This same general pattern was obtained at every developmental stage in the $\mathrm{S}_{\mathrm{L}}=30$ and $25 \%$ o series, with low $S_{\text {U }}$ causing partial or complete avoidance. The results of the $S_{L}=20 \%$ o series differed in that the primary concentration was always located at the bottom with a secondary concentration at the surface in control columns and at or below the interface in stratified columns. 
Disregarding the detailed distribution of larvae, the data were expressed quantitatively in two ways; as an activity index and as an orientation index. The activity index, $I_{A}$, is merely the ratio of larvae counted in all 10 levels to the total number of larvae introduced into the column at time $t_{0}$ times 100 . The orientation index can be expressed as :

$$
I_{o}=\frac{N_{U}-N_{L}}{N_{U}+N_{L}} \times 100
$$

where: $\mathrm{N}_{\mathrm{U}}=$ total number of larvae in upper half of column. where: $\mathrm{N}_{\mathrm{L}}=$ total number of larvae in lower half of column.

This index ranges from 100 to -100 , with 0 indicating equal distribution between the two layers, and -100 indicating complete avoidance of the upper layer. Lagerspertz and Matilla (1961) used this index in studying the salinity responses of several amphipod and isopod species. The values for both indices in the present study are presented in Table I.

The activity index for control columns was $70-90$ for the $S_{L}=30 \%$ series with a slight increase from Zoea I to IV. In the $S_{L}=25 \%$ series, $I_{A}$ for control columns was in the same range but with no apparent increase with developmental age. At $\mathrm{S}_{\mathrm{L}}=20 \%, \mathrm{I}_{\mathrm{A}}$ for the control was lower, $50-70$ for Zoea $\mathrm{I}$ and II, 60-80 for Zoea III and IV. $I_{A}$ for each developmental stage decreased as $S_{V}$ was reduced from $S_{U}=S_{L}$ to $S_{U}=15 \%$ in all three experimental series. The decrease in $I_{\mathbf{A}}$ was more marked in the earlier developmental stages and in the $\mathrm{S}_{\mathrm{L}}=20 \%$ series. $\mathrm{I}_{\mathrm{A}}$ tended to decrease with time when $\mathrm{S}_{\mathrm{U}}=15 \%$, but not at higher $S_{\mathbb{U}}$ 's.

The orientation index for control columns at $\mathrm{S}_{\mathrm{L}}=30 \%$ and $25 \%$ was 40 or above except in a few anomalous instances when an unusually high percentage of larvae was present in the lowest $4 \mathrm{~cm}$ segment of the column during the early part of the experiment, in which case $\mathrm{I}_{0}$ was $c a$. 10 . At $\mathrm{S}_{\mathrm{L}}=20 \%$, $\mathrm{I}_{\mathrm{o}}$ for the control column was usually much lower, in the 10 to -40 range. Regardless of $S_{L}, I_{O}$ decreased with decreasing $\mathrm{S}_{\mathrm{U}}$; in most cases $\mathrm{I}_{0}<-60$ at $\mathrm{S}_{\mathrm{U}}=15 \%$. In most tests $I_{0}$ tended to increase with time whenever the initial value was greater than 0 and to decrease whenever the initial value was less than 0 . This trend was apparent regardless of the $\Delta S\left(=S_{L}-S_{V}\right)$.

The most obvious question is whether avoidance of a water mass is a function of an absolute salinity or whether it is a function of $\Delta \mathrm{S}$. To examine the possibilities, $\mathrm{I}_{0}$ values for 60 min were plotted on a graph of $\Delta \mathrm{S}$ versus $\mathrm{S}_{\mathrm{L}}$ for each zoeal stage (Fig. 4a-d).

If avoidance is based on an absolute salinity, then a line separating the regions of avoidance and nonavoidance would be expressed by $\Delta S=S_{L}-$ a where $a=S_{L}$ where $\Delta S=0$, whereas if avoidance is based on the salinity difference exclusively, such a line would be expressed by $\Delta \mathrm{S}=\mathrm{b}$ for all $\mathrm{S}_{\mathrm{L}}$. If avoidance is based on one factor over part of the range of $S_{L}$ and the other over the rest of the range, a family of curves between these two models would be generated.

The avoidance response of Zoea $\mathrm{I}$ is based on an absolute salinity of about $20 \%$ or slightly less when $\mathrm{S}_{\mathrm{L}}<25 \%$, and $\Delta \mathrm{S}=8 \%$ when $\mathrm{S}_{\mathrm{L}}>25 \%$. Similarly, for Zoea II, the avoidance response is a function of an absolute salinity of 
about $22 \%$ when $S_{L}<25 \%$ and $\Delta S=5 \%$ when $S_{L}>25 \%$. The tendency for the $\mathrm{I}_{0}$ value for $\mathrm{S}_{\mathrm{L}}=30 \%$ to be less than that for $\mathrm{S}_{\mathrm{L}}=25 \%$ at each $\Delta \mathrm{S}$ for these two stages cannot be explained.

For Zoea III and Zoea IV the avoidance response is a function of an absolute salinity of about 20\%. Actually, the slope of the line is steeper than predicted by the first model, but this may result in part from the imprecision of $I_{0}$ and

TABLE I

Activity and orientation indices for each developmental stage. The activity index in italic type, the orientation index in roman type

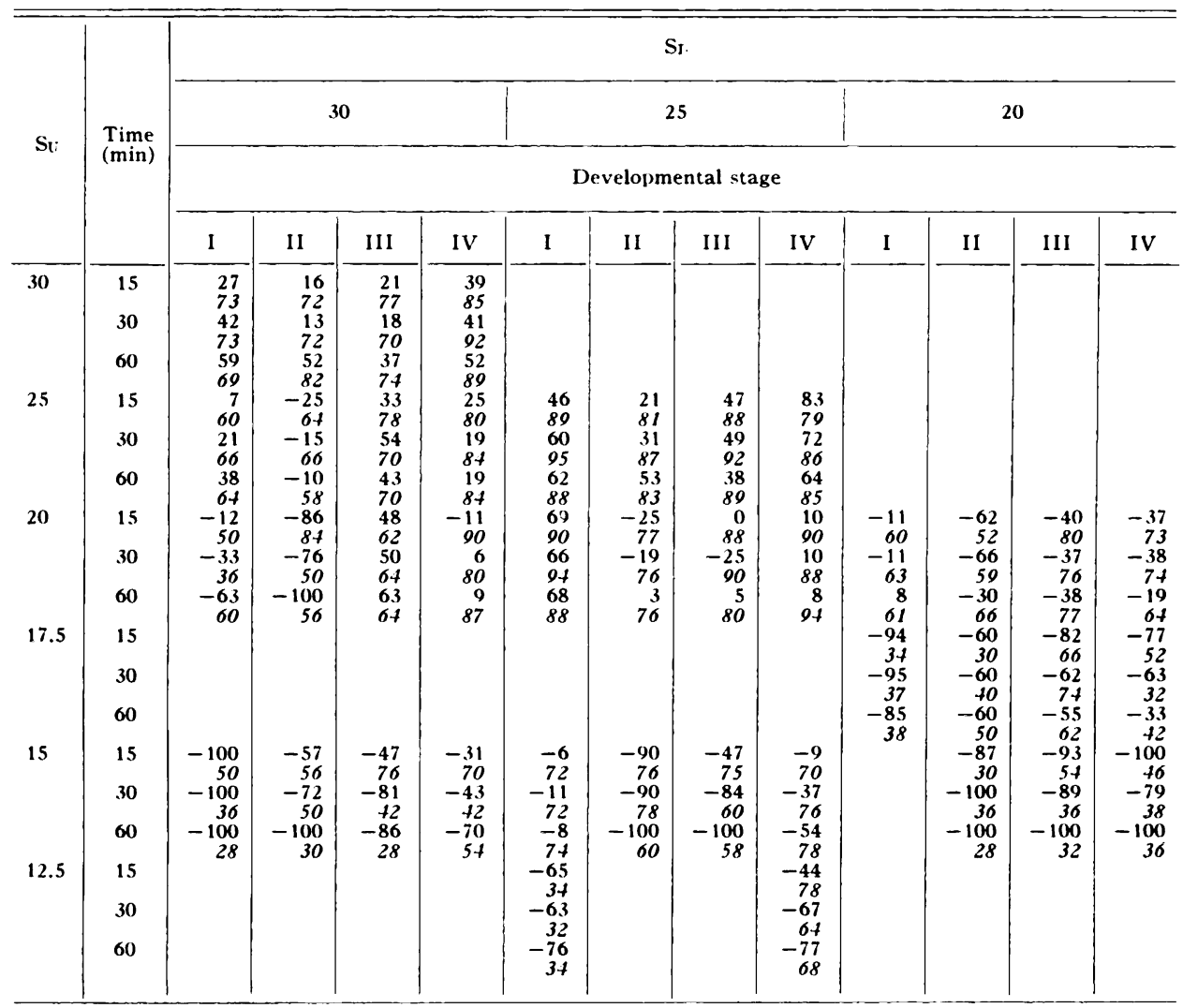

the fact that the experiments on which the results are based were carried out over a five month period.

In the single long-term experiment lasting 25 hours, $I_{\mathbf{A}}$ in two unstratified columns was 80-98 at each observation. For the first 7 hours in one column and the first 2 hours in the other, $I_{0}$ was $40-50$, increasing to $60-90$ for the remainder of the experiment. The shift in $I_{0}$ in both cases resulted from a reduction in the percentage of larvae in the bottom-most level. Perhaps these larvae were slightly damaged during the injection into the column, resulting in a negative 
light response which was slowly reversed with time. In any case, no periodic variation was noted in either $I_{A}$ or $I_{0}$. $I_{0}$ did not return to the low initial value of 40 after 24 hours, but remained at the high value of 80 reached some time after the experiment was started.

The effect of larval density was briefly examined in a single experiment. At a density of 1 larva per $40 \mathrm{ml}$, the density used in the main series of tests, $I_{0}=40$. $I_{A}=80$ to 90 . When the larval density was reduced by half to 1 larva per $80 \mathrm{ml}$,
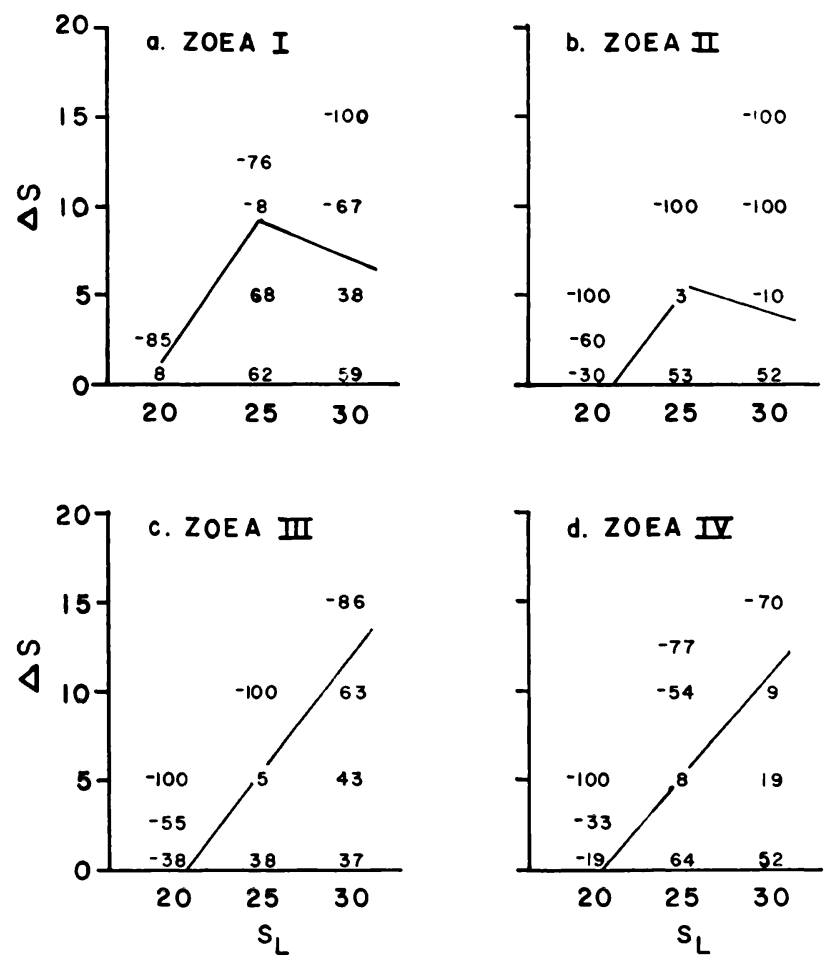

FIgURE 4. The orientation index ( $\left.I_{0}\right)$ values measured after $60 \mathrm{~min}$ are plotted on a matrix of salinity differences across the discontinuity $(\Delta \mathrm{S})$ v'ersus the salinity of the lower layer $\left(S_{L}\right)$ for each zoeal instar. The solid line in each case approximates the $I_{0}=0$ line. Values of $I_{0}<0$ represent avoidance of the upper water layer, values of $I_{0}>0$ represent nonavoidance.

$I_{0}=50$ to $60, I_{A}=70$ to $80 . \quad A x^{2}-$ test on the data for each 4-cm segment showed no significant difference in the distribution on the two columns, but, as $I_{o}$ reveals, there was a slight tendency for a greater proportion of the larvae to enter the upper stratum at the lower overall larval density. I doubt that the use of lower larval densities would have changed the results of the main series just described, however.

The results described above were derived from larvae of several females with different prehistories, especially with regard to season. There is no a priori reason why larvae from different females, different seasons and different geographical 
locations should behave in exactly the same manner in response to any given stimulus. However, no attempt has been made to test the effect of these variables. Agreement of results from replicated controls suggests that these variables are unimportant, with the possible exception of geographical location.

In experiments with antennectomized and uropodectomized Zoea III's, the ability of amputees to traverse an unstratified column was tested first. Antennectomized and uropodectomized larvae, after introduction into the column, moved slowly upward. Orientation of the longitudinal body axis varied erratically from 0 to $90^{\circ}$ from the vertical. It took 2 to 3 minutes for each larva to reach the surface. Non-amputees from the same culture traversed the column in about 1 minute, with very precise orientation of the longitudinal body axis as described above (Fig. 2a).

In a stratified column $(15 / 30)$, the behavior of all three groups, non-amputees, antennectomized, and uropodectomized larvae, was the same as that of control larvae in the main series of experiments. Upon encountering the discontinuity, each larva responded with telson flips, downward swimming, and sinking, which resulted in complete avoidance of the upper stratum. Each larva repeated these responses continuously over a 5 minute observation period after which it was removed from the column and another larva introduced.

\section{Discussion}

Despite differences in apparatus and procedure, several authors have observed a definite behavioral response to salinity discontinuities and have been able to identify a critical salinity difference causing avoidance. Harder (1968) listed species from seven phyla which have been shown to respond: Protozoa, Ctenophora, Chaetognatha, Annelida (Polychaeta), Mollusca, Arthropoda (Crustacea), and Chordata (Larvacea and Teleostei). To Harder's list may be added Mercenaria mercenaria trochophores (Turner and George, 1955), Phyllodoce larvae (Lyster, 1965), several copepod species and Pisidia longicornis Zoea I and II (Lance, 1962) and Homarus americanus Zoea I (Scarratt and Raine, 1967).

Detailed comparisons of responses will only be made among the various decapod crustaceans which have been studied to date. At each developmental stage, the salinity which causes aroidance by $P$. longicarpus is different. The most sensitive stage is Zoea II. Lance (1962) did not observe any difference in the response of the zoeal instars of Pisidia longicornis. Scarratt and Raine (1967) made no attempt to assess the effect of developmental age on the avoidance response.

Despite differences in response of each developmental stage, the avoidance salinity was in every case higher than the minimum survival salinity, indeed even the minimum optimal salinity. $P$. longicarpus larvae at every instar partially avoided $20 \%\left(I_{0} \simeq 0\right)$ and completely avoided lower salinities $\left(I_{0}<0\right)$. Complete development occurred as readily at $18.0 \%$ as at $30.5 \%$ and was still possible at $15.5 \%$ though with a marked reduction in survival rate. Only at $13.0 \%$ was survival and development completely halted (Roberts, 1971). Pisidia longicornis exhibited more than 50\% mortality in 20 hours at salinities below $14.4 \%$ with $100 \%$ mortality at about $12.6 \%$ for both zoeal instars (Lance, 1964). Both zoeal instars avoided 18\% almost completely and $14.4 \%$ completely (Lance, 1962). It should be noted, however, that the mortality rates in the present study and in 
Lance's work are not exactly comparable (see Roberts, 1971). Scarratt and Raine (1967) found that Homarus americanus Zoea I avoided 21.4\% although they can survive at least in water of $20.7 \%$ and perhaps even in water of only $13.5 \%$ salinity.

Lance (1962) attempted to assess the effect of $\Delta \mathrm{S}$ by setting up multilayered columns (each layer $5 \mathrm{~cm}$ thick) with $\Delta \mathrm{S}=3.6$ or $1.8 \%$ between each layer. Both zoeal instars concentrated in strata with a salinity between 29 and $32.5 \%$ with a few entering water of only $25 \%$ salinity when $\Delta S=1.8 \%$, and only $21.5 \%$ when $\Delta \mathrm{S}=3.6 \%$. Larvae entering water layers of 21.5 and $25 \%$ calinity were, in my view, merely "sampling" these water masses and were not "permanent residents." Failure to enter water of $18 \%$ resulted from the larvae having responded already to water of a slightly higher salinity.

In the present study, a different approach was employed; $S_{\mathrm{I}}$, was progressively reduced to determine changes in the salinity which cause avoidance. In this way it was shown that $\Delta \mathrm{S}$ and absolute salinity both are important in the response of the larvae. Apparently at later developmental stages, $\Delta S$ becomes less important. In any case, one would predict that larvae in a multilayered column would concentrate at a level with salinity between 20 and $25 \%$ with little penetration to levels with salinity between 17.5 and $20 \%$. This conclusion is derived from the fact that the primary concentration of larvae in experiments with $S_{\mathrm{L}}=$ $20 \%$ was located at the bottom with a very small percentage near the interface. This prediction agrees with the results of Lance (1962) already noted, although not tested here.

Harder (1952b) noted that zooplankters, mostly copeporls, aggregate at the discontinuity between water masses of differing salinity or temperature. In subsequent experiments $(1954,1957)$, he detected a response by copepods to salinity differences as small as $0.20 \%$. Even when the discontinuity was produced by disrupting the ionic ratios by the addition of $\mathrm{NaCl}$, copepods responded as in previous tests. When non-electrolytes such as sugar and glycerol were added to the water in varying amounts to produce concentration discontinuities, the animals again responded by aggregating at the discontinuity. He hypothesized from these results that the effective stimulus for the response was density or viscosity. To test this, he set up a stratified column with $\Delta S=14.3 \%$, a sugar difference of $25 \%$, but no density difference. In this case, no aggregation occurred at the discontinuity. Since the viscosity of the two strata differed, Harder concluded that density provided the stimulus. There are two criticisms of this conclusion, however. First, he has not shown that the density of the stratum avoided was the same for both thermal and saline discontinuities. The response to a thermal discontinuity could be simple orthokinesis (see for example Welsh, 1932), while the response to a saline discontinuity could be to some non-density property. This leads to the second criticism. Harder's results clearly show that the salinity response of copepods is not based on detection of ionic concentration. However. sucrose addition affects all colligative properties, not just density and viscosity. Osmotic pressure could well have been the effective stimulus in producing the response. Further investigation is necessary to clarify this point.

The amphipod, Gammarus, and the isopod, Asellus, can discriminate between water of 0 and $6 \%$ (Lagerspetz and Mattila, 1961). Using antennectomized 
animals, they showed that the sensory receptors are localized on A 1 and A 2 of Gammarus, and on one or both of these structures of Asellus. In Pagurus larvae, however, there is no evidence of localization of receptors on A 1 and/or A 2. Chemoreceptors have been found on the dactyls of the pereiopods and on the maxillae of adult decapods, although these are not necessarily sensitive to salt solutions (Hodgson, 1955). No further efforts were made to isolate potential receptor sites with $P$. longicarpus larvae because of difficulty in successfully amputating suspect structures.

Larvae of $P$. longicarpus are capable of detecting a $\Delta \mathrm{S}$ of only $2.5 \%$ and probably less. There are two types of data to support this contention: direct observation of individual larvae and differences in $I_{0}$. Larvae passing through any discontinuity used in the experiments exhibited the flip response irrespective of whether or not they ultimately avoided the upper stratum. Further, $\mathrm{I}_{0}$ decreased stepwise with each 2.5 or $5 \%$ decrease in $S_{U}$ regardless of $S_{L}$. This latter result is also apparent in the data for Pisidia longicornis (Lance, 1962).

The flip response is a clearcut avoidance response or klinokinesis. The sinking response is a cessation of all swimming activity. The downward swimming response, which can at times be very rapid and is well oriented with the longitudinal body axis as in upwards swimming, is not clearly understood. Ewald (1912) concluded that nauplii of Balanus perforatus become photonegative when placed in water of reduced salinity. Lyon (1906) had previously concluded the same thing for Palaemonetes larvae. In both cases the results can be explained in another way since the experiments were not adequately controlled. In the present experiments, downward swimming could be explained as a reversal of the photo-response, or by the reversal of the georesponse. No attempt has yet been made to discriminate between these possibilities. The results obtained from the $S_{L}=20 \%$ series suggest that one or both of these responses have been reversed.

Regardless of which response was reversed, larvae tested in columns in which complete avoidance of the upper stratum was noted also had a low $\mathrm{I}_{\mathbf{A}}$. The uncounted larvae could be seen oriented as if swimming but not moving up off the bottom (hence not counted). This suggests a continued active avoidance even though the larvae were in a suitable salinity. Any larva returning to a photopositive (or geonegative) response, would swim upward to the interface and again experience a reversal of the photo-(geo)-response.

I am indebted to Dr. Langley Wood, chairman of my graduate committee, for his help and encouragement. I also appreciate the critical efforts of Drs. Morris L. Brehmer and Marvin L. Wass and Messrs. John J. Norcross and Willard A. Van Engel. Dr. Edwin Joseph provided a constant temperature bath. Figures were prepared by Mrs. Jane S. Davis and Mrs. K. Stubblefield.

I owe special thanks to my wife, Beverly Ann, who cultured many of the larvae used in these experiments and constantly encouraged me.

During the course of this study I was the recipient of a National Science Foundation Graduate Fellowship. 


\section{SUMMARY}

1. Each zoeal instar of $P$. longicarpus was exposed to salinity discontinuities of varying magnitudes. Three distinct behavioral responses were observed: telson flips regardless of the magnitude of the discontinuity; downward swimming when the magnitude of the discontinuity was moderate; passive sinking when the magnitude of the discontinuity was extreme.

2. All zoeal instars avoided water with a salinity of $c a .20 \%$ or less, well within the range of salinity permitting complete development to the juvenile.

3. Avoidance of low salinity layers in stratified columns by Zoea I and II appeared to be a function of an absolute salinity $(\mathrm{S} \simeq 20-22 \%)$ when the salinity of the lower layer $\left(S_{L}\right)$ was less than $25 \%$ and a function of salinity difference $(\Delta \mathrm{S})$ when $\mathrm{S}_{\mathrm{I}}$, was greater than $25 \% \quad(\Delta \mathrm{S} \simeq 8 \%$ for Zoea $\mathrm{I}$; $\Delta \mathrm{S} \simeq 5 \%$ for Zoea II). Avoidance of low salinity layers by Zoea III and IV appeared to be a function of absolute salinity $\left(S \simeq 20 \%\right.$ ) regardless of $S_{L}$ over the range of $S_{L}$ tested.

4. Evidence is presented that the antennules and antennae may not be involved in detection of salinity discontinuities.

\section{LITERATURE CITED}

Costlow, J. D., Jr., C. G. Bovkhout and R. Monroe, 1960. The effect of salinity and temperature on larval development of Sesarma cincreum (Bosc) reared in the laboratory. Biol. Bull., 118: 183-202.

Costlow, J. D., JR., C. G. Bookhout AND R. Monroe, 1962. Salinity-temperature effects on the larval development of the crab, Panopeus herbstii Milne-Edwards, reared in the laboratory. Physiol. Zool., 35: 79-93.

Costlow, J. D., JR., C. G. Book hout and R. Monroe, 1966. Studies on the larval development of the crab, Rhithropanopeus harrisii (Gould). I. The effect of salinity and temperature on larval development. Physiol. Zool., 39: 81-1C0.

EwALD, E. F., 1912. On artificial modification of light reactions and the influence of electrolytes on phototaxis. J. Exp. Biol., 13: 591-612.

HaRder, W., 1952a. Einige Geräte zur Herstellung von Wasserschichten verschiedener Dichte. Kurze Mitt. Fischbiol. Abt. Max-Planck-Inst. Mecresbiol. Wilhelms, 1: 21-27.

Harder, W., 1952b. Uber das Verhalten von Zooplankton in geschichtetem Wasser. Kurze Mitt. Fischbiol. Abt. Max-Planck-Inst. Mecresbiol. Wilhelms, 1: 28-43.

HaRder, W., 1954. Weitere experimentelle Untersuchungen über das Verhalten von Copepoden gegenüber Sprungschichten. Kuric Mitt. Fischbiol. Abt. Max-Planck-Inst. Mecresbiol. Wilhelms, 4: 1-47.

Harder, W., 1957. Verhalten von Organismen gegenüber Sprungschichten. Annéc Biol., 33 : 227-232.

Harder, W., 1968. Reaction of plankton organisms to water stratification. Limnol. Oceanogr., $13: 156-168$

Hodgson, E. S., 1955. Problems in invertebrate chemoreception. Quart. Reح. Biol., 30: 331347.

Lagerspertz, K., And M. Mattila, 1961. Salinity reactions of some fresh- and brackish-water crustaceans. Biol. Bull., 120: 44-53.

LANCE, J., 1962. Effects of water of reduced salinity on the vertical migration of zooplankton. J. Mar. Biol. Ass. U. K., 42: 131-154.

LANCE, J., 1964. The salinity tolerances of some estuarine planktonic crustaceans. Biol. Bull., 127 : 108-118.

Lyon, E. P., 1906. Note on the heliotropism of Palaemonctes larvae. Biol. Bull., 12: 23-25. 
Lyster, I. H. J., 1965. The salinity tolerance of polychaete larvae. J. Anim. Ecol., $34: 517-$ 527.

Roberts, M. H., JR., 1971. Larval development of Pagurus longicarpus Say reared in the laboratory. II. Effects of reduced salinity on larval development. Biol. Bull., 140: 104-116.

Scarratt, D. J., and G. E. Raine, 1967. Avoidance of low salinity by newly hatched lobster larvae. J. Fish. Res. Board Can., 24 : 1403-1406.

Shelford, V. E., 1915. Principles and problems of ecology as illustrated by animals. $J$. Ecol., 3: 1-23.

Turner, H. J., JR., And C. J. George, 1955. Some aspects of the behavior of the quahaug Venus mercenaria during the early stages. 8th Rep. Intest. Shellf., Mass. Dept. Nat. Res., Diz'. Mar. Fish., Commonzealth Mass., 8: 5-14.

Welsh, J. H., 1932. Temperature and light as factors influencing the rate of swimming of the larvae of the mussel crab, Pinnotheres maculatus Say. Biol. Bull., 63: 310-326. 